\title{
Correction to: Advances in Treatments for Aortic Valve and Root Diseases
}

\author{
Khalil Fattouch, Patrizio Lancellotti, Mani A. Vannan, \\ and Giuseppe Speziale
}

\section{Correction to: \\ K. Fattouch et al. (eds.), Advances in Treatments for Aortic Valve and Root Diseases, https://doi.org/1 0.1007/978-3-319-66483-5}

This book was initially published with errors in the following chapters, which have been updated now.

Chapter 2

https://doi.org/10.1007/978-3-319-66483-5_2

Permissions have been received retroactively from Dr. R. H. Anderson for the use of Figures 2.1. and 2.2. in Chapter 2.

On Page 32, in figure 2.6 legend, line 4, replaced "bisecting" with "off-center".

On Page 32, in figure 2.6 legend, line 5, replaced "off-center" with "bisecting".

On Page 32, line 4, replaced "bisecting" with "off-center".

On Page 32, line 6, replaced "off-center" with "bisecting".

Chapter 3

https://doi.org/10.1007/978-3-319-66483-5_3

Permission has been received retroactively from Dr. R. H. Anderson for the use of Figure 3.2. in Chapter 3.

The updated online version of these chapters can be found at https://doi.org/10.1007/978-3-319-66483-5_2

https://doi.org/10.1007/978-3-319-66483-5_3 